\title{
Effects of aerobic exercise on fatigue level and quality of life in type-2 diabetes people, A cross - sectional observational study
}

\author{
Khushbu D. Rathod ${ }^{1 *}$, Jaspreet Kaur Kang² \\ ${ }^{1}$ Lecturer, ${ }^{2}$ Principal, ${ }^{1}$ Mahatma Gandhi Physiotherapy College, Ahmedabad, Gujarat, ${ }^{2} \mathrm{JG}$ College of Physiotherapy, Ahmedabad, Gujarat, \\ India \\ *Corresponding Author: Khushbu D. Rathod \\ Email: khushbu101291@gmail.com
}

\begin{abstract}
Introduction: Fatigue, sleepiness, tiredness, lacking of energy and exhaustion are words commonly used in everyday life interchangeably. Fatigue may also be related to psychological factors such as depression, emotional distress, and it's also related to the diagnosis or intensity of diabetes self-management regimens. It's also related to lifestyle issues such as lack of exercise, overweight, and mostly common in type2 diabetes. Diabetes mellitus a major public health problem. Aerobic exercise is accepted as a therapeutic strategy for type-2 diabetes because of its beneficial effects on glycaemic profile.

Objective: The purpose of the study was to observe the effects of aerobic exercise on fatigue level and quality of life in type -2 diabetes persons.

Materials and Methods: 12 subjects ( 7 females; 5 males) randomly selected were given aerobic exercise given for 1 month. The effect of aerobic exercise were measured by Patients health questionnaire (PHQ-9) (quality of life) and Fatigue severity scales (FSS) for fatigue levels. The means of pre and post intervention data were measured using a paired $t$-test.

Conclusion: There was significant difference between pre and post PHQ-9 \&FSS after 4 weeks of aerobic exercise in type 2 diabetes mellitus patients.
\end{abstract}

Keywords: Aerobic exercise, Diabetes mellitus, PHQ-9, FSS.

\section{Introduction}

Fatigue, sleepiness, tiredness, lacking of energy, and exhaustion are words commonly used in everyday conversations. Fatigue is also defined as a multi causal, multidimensional sensation in which we can include physiological, psychological, and situational components. Fatigue is a common and painful complaint among people with type 2 diabetes. $^{2}$ Tiredness, lack of energy, and exhaustion like symptoms are also found in other medical disorders. Fatigue is more in type-2 diabetes patients, impacting the quality of life (QoL) due to the complex management strategies. Suggested factors include hyper/hypoglycaemia, ${ }^{3}$ number of complications, ${ }^{4-5}$ and depression. ${ }^{6}$ Fatigue impacts functional capacity which has been seen in patients with other chronic disorders. ${ }^{7,8}$ Functional capacity of type 2 diabetes patients is further affected due to due to low cardio respiratory fitness ${ }^{9}$ low physical activity levels ${ }^{10}$ and high body mass index (BMI). Previous studies have suggested that individuals with diabetes covered less distance during a 6 minute walk test (6MWT) as compared to age and sex matched controls. However, the impact of fatigue on QoL and functional status has not yet been investigated in patients with diabetes ${ }^{11}$. Previous studies have focussed on specific causes of fatigue in diabetes patients, and concluded that multiple factors contribute to fatigue in patients with chronic illness. ${ }^{12,13}$ The factors responsible for fatigue in type- 2 diabetes patients are physiological components of the underlying disease, complications which occur due treatment and the psychological components which include depression and anxiety. ${ }^{14,21}$ Hyperglycaemia is also one of the causes for fatigue in type- 2 diabetes patients ${ }^{16}$.
Numerous complications like sleep problems, ${ }^{17}$ chronic pain, ${ }^{18}$ overweight ${ }^{19}$ and obesity may cause higher fatigue levels. ${ }^{20}$ The relationship between fatigue and the possible physiological and psychological factors in individuals with type 2 diabetes is still unknown. ${ }^{22,24}$ Aerobic exercises are one of the available strategies for type 2 diabetes patients. Aerobic exercise training is used in health promotion and different rehabilitation programs to improve physical strength \& endurance. They are also effective in reducing fatigue levels and maintain the quality of life in type-2 diabetes people. Therefore the purpose of present study was to observe the effect of aerobic exercises on fatigue levels and quality of life in type- 2 diabetes patients.

\section{Materials and Methods}

Total 12 type-2 diabetic patients were recruited from a clinic in Ahmadabad, Gujarat. A cross - sectional observational study design was used for the study. The included participant were diabetic patients with disease duration $>2$ years, age between 40 to 50 years, 5males, \& 7-females. Patients with any neurological, musculoskeletal or cardiovascular problems, any recent surgery were excluded. Ethical clearance was taken from institutional ethics committee. The participants were informed about the procedure thoroughly and signed informed consent obtained from them.

According to ACSM guidelines, an aerobic exercise protocol was designed for the type- 2 diabetic patients. Pre intervention, FSS (fatigue severity scale) and PHQ-9 (patients health questionairre -9) were measured. Aerobic exercises were done for 45 minutes, 5 days / week, for 4 
weeks. After completion of 4 weeks, the FSS \& PHQ-9 scores were again taken

The following exercise was given to every participant.

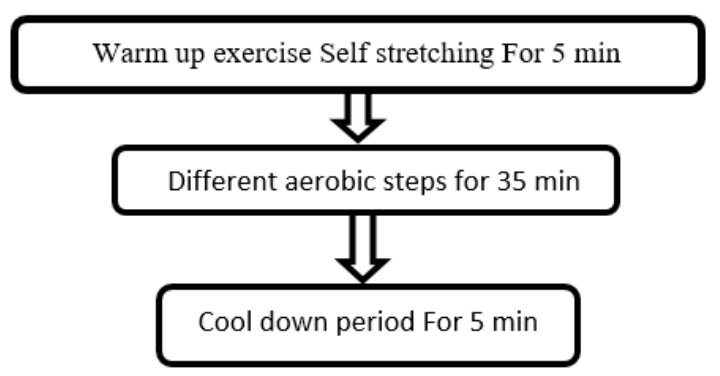

\section{Statistical analysis}

The statistical calculation was done using SPSS software version 20. Statistical significance was evaluated between pre \& post score of FSS \& PHQ-9 by using paired t-test. Significance was assumed at $\mathrm{p}<0.05$.

\section{Results}

Statistical significant differences were found in PHQ 9 scores and FSS scores $(\mathrm{p}<0.05)$. The post intervention mean values suggest improvements for both scores (Table 1 and Table 2)

Table 1: The PHQ-9 questionaire scores pre and post intervention $(\mathrm{n}=12)$

\begin{tabular}{|c|c|c|c|}
\hline PHQ-9 Score & Mean \pm SD & t value & P value \\
\hline Pre & $16.00 \pm 1.47$ & 11.89 & 0.001 \\
\cline { 1 - 2 } Post & $10.16 \pm 1.11$ & & \\
\hline
\end{tabular}

Table 2: The FSS e scores pre and post intervention $(n=12)$

\begin{tabular}{|c|c|c|c|}
\hline FSS Score & Mean \pm SD & t value & P value \\
\hline Pre & $45.5 \pm 10.67$ & 11.57 & 0.001 \\
\hline Post & $31.5 \pm 8.42$ & & \\
\hline
\end{tabular}

\section{Discussion}

The purpose of the study was to observe the effect of aerobics exercise on fatigue level \& quality of life in type- 2 diabetes patients. The results of the current study demonstrates that fatigue level is decreased \& quality of life improved after aerobic exercise in type- 2 diabetes patients.

Similar to the results of this study in chronic conditions or diseases, aerobic exercises have resulted in reduction in fatigue levels. Previous studies conducted on community dwelling older adults also suggest that increasing physical activity levels had important implication in reducing fatigue level. ${ }^{25}$ Similarly a study on multiple sclerosis patients, who received combination therapy including aerobic exercise also suggests that aerobic exercise helpful to reduce fatigue level and also improve quality of life. ${ }^{26}$ It is important for health care providers treating the patient with type 2 diabetes to address their fatigue issues. Health care providers should use complaints of fatigue as a starting point for further evaluation of co morbid conditions. In conclusion, results of this study suggested that interventions strategies should be developed to reduce the burden of fatigue in individuals with type 2 diabetes.

\section{Source of funding \\ Self}

\section{Conflict of interest}

Nil.

\section{References}

1. Rupali Singh, Cynthia Teel, Carla Sabus, Patricia McGinnis. Patricia Kluding, Fatigue in Type 2 Diabetes: Impact on Quality of Life and Predictors PLOS ONE |

DOI:10.1371/journal.pone.0165652 November 8, 2016.

2. Singh R, Kluding PM. Fatigue and related factors in people with type 2 diabetes. The Diabetes educator. 2013; 39(3):3206. Epub 2013/03/12. doi: 10.1177/0145721713479144 PMID: 234751

3. Testa MA, Simonson DC. Health economic benefits and quality of life during improved glycemic control in patients with type 2 diabetes mellitus: a randomized, controlled, double-blind trial. JAMA 1998;280(17):1490-6. Epub 1998/11/11. PMID: 9809729.

4. Glasgow RE, Ruggiero L, Eakin EG, Dryfoos J, Chobanian L. Quality of life and associated characteristics in a large national sample of adults with diabetes. Diabetes Care 1997;20(4):5627. Epub 1997/ 04/01.

5. Brown GC, Brown MM, Sharma S, Brown H, Gozum M, Denton P. Quality of life associated with diabetes mellitus in an adult population. J Diabetes Complications 2000;14(1):1824. Epub 2000/08/05. S1056-8727(00)00061 -1

6. Goldney RD, Phillips PJ, Fisher LJ, Wilson DH. Diabetes, depression, and quality of life: a population study. Diabetes Care 2004;27(5):1066-70.

7. Coleman EA, Goodwin JA, Coon SK, Richards K, Enderlin C, Kennedy R, et al. Fatigue, sleep, pain, mood, and performance status in patients with multiple myeloma. Cancer Nurs 2011; 34(3):21 9-27. Epub 2011/04/28. doi: 10.1097/NCC.0b013e3181f9904d 00002820-20110500000009

8. van Weert E, Hoekstra-Weebers J, Otter R, Postema K, Sanderman R, van der Schans C. Cancerrelated fatigue: predictors and effects of rehabilitation. Oncol 2006;11(2):18496. Epub 2006/02/ 16. 11/2/184 [pii] doi:

10.1634/theoncologist.

9. Wei M, Gibbons LW, Kampert JB, Nichaman MZ, Blair SN. Low cardiorespiratory fitness and physical inactivity as predictors of mortality in men with type 2 diabetes. Ann Intern Med 2000;132(8):605-11.

10. Morrato EH, Hill JO, Wyatt HR, Ghushchyan V, Sullivan PW. Physical activity in U.S. adults with diabetes and at risk for developing diabetes, 2003. Diabetes Care. 2007;30(2):203-9. Epub 2007/01/30.doi: 10.2337/dc06-1128

11. Ingle L, Reddy P, Clark AL, Cleland JG. Diabetes lowers sixminute walk test performance in heart failure. $\mathrm{J} \mathrm{Am} \mathrm{Coll}$ Cardiol 2006;47(9):1909-10. Epub 2006/05/10. doi: 10.1016/j.jacc.2006.02.005

12. Gibson H, Edwards RH. Muscular exercise and fatigue. Sports Med 1985;2(2):120-32.

13. Walker GC, Cardenas DD, Guthrie MR, McLean A Jr., Brooke MM. Fatigue and depression in braininjured patients correlated with quadriceps strength and endurance. Arch Phys Med Rehabil 1991;72 (7):469-72. 
14. Portenoy RK, Itri LM. Cancer-related fatigue: guidelines for evaluation and management. Oncol 1999;4(1):1-10. Morsch CM, Goncalves LF, Barros E. Health-related quality of life among haemodialysis patients - relationship with clinical indicators, morbidity and mortality. J Clin Nurs 2006;15(4):498-504. doi: 10.1111/j.1365-2702.2006.01349.x

15. Weijman I, Kant I, Swaen GM, Ros WJ, Rutten GE, Schaufeli WB, et al. Diabetes, employment and fatigue-related complaints: a comparison between diabetic employees, "healthy" employees, and employees with other chronic diseases. J Occup Environ Med 2004; 46(8):828-36.

16. Resnick HE, Redline S, Shahar E, Gilpin A, Newman A, Walter R, et al. Diabetes and sleep disturbances: findings from the Sleep Heart Health Study. Diabetes Care 2003;26(3):7029.

17. Rijken PM, Dekker J, Dekker E, Lankhorst GJ, Bakker K, Dooren J, et al. Clinical and functional correlates of foot pain in diabetic patients. Disabil Rehabil 1998;20(9):330-6.

18. Rayburn WF. Diagnosis and classification of diabetes mellitus: highlights from the American Diabetes Association. J Reprod Med 1997;42(9):585-6.

19. Resnick HE, Carter EA, Aloia M, Phillips B. Cross-sectional relationship of reported fatigue to obesity, diet, and physical activity: results from the third national health and nutrition examination survey. J Clin Sleep Med: Am Acad Sleep Med 006;2(2):163-9.

20. Anderson RJ, Freedland KE, Clouse RE, Lustman PJ. The prevalence of comorbid depression in adults with diabetes: a meta-analysis. Diabetes Care 2001;24(6):1069-78.

21. Egede LE, Zheng D. Independent factors associated with major depressive disorder in a national sample of individuals with diabetes. Diabetes Care 2003;26(1):104-11.
22. Katon W, von Korff M, Ciechanowski P, Russo J, Lin E, Simon G, et al. Behavioral and clinical factors associated with depression among individuals with diabetes. Diabetes Care 2004; 27(4):914-20.

23. Ryerson B, Tierney EF, Thompson TJ, Engelgau MM, Wang J, Gregg EW, et al. Excess physical limitations among adults with diabetes in the U.S. population, 1997-1999. Diabetes Care 2003; 26 (1):206-10.

24. Smets EM, Garssen B, Bonke B, De Haes JC. The Multidimensional Fatigue Inventory (MFI) psychometric qualities of an instrument to assess fatigue. J Psychosom Res 1995;39(3):315-25.

25. Fritschi C, Quinn L, Hacker ED, Penckofer SM, Wang E, Foreman M, et al. Fatigue in women with type 2 diabetes. Diabetes Educ 2012;38(5):662-72.

How to cite this article: Rathod KD, Kang JK. Effects of aerobic exercise on fatigue level and quality of life in type-2 diabetes people, A cross - sectional observational study. J Soc Indian Physiother 2020;4(1):3-5 